\title{
ROOT CAUSE ANALYSIS OF AN ARTILLERY BREECHBLOCK AND ITS IMPROVED
}

\author{
Wenyuan Song, Jianshe Kang, Lianyan Shi, Yabin Wang \\ 6th department, Mechanics engineering college, Shijiazhuang, Hebei, 050003, China, Email: \\ mumi13@163.com
}

\begin{abstract}
The breechblock failure is a repeatedly failure with high frequency on artillery. And it is unable to prevent effetely by Reliability Centered Maintenance. A Root Cause Analysis method, which is improved according to the feature of artillery, is used to analyze the breechblock failure. It was validated that one key root cause of this failure is the problem in pry-axis design of breechblock.
\end{abstract}

Key words: Root Cause Analysis; Artillery Breechblock; Improved method

\section{INTRODUCTION}

As an important unit of modern artillery, breechblock is used to stick into the shell pumer, closedown the chamber with powder flask when firing, and draw out the powder flask after firing. It is one of the highest frequency betake machine on artillery, especially in training. According to statistics, there is approximately 30 percent artillery failure caused by breechblock ${ }^{[l]}$. So frequency failure of the breechblock will disturb the normally training and foreclose the campaign effect of artillery. Although some of them can be prevented by traditional prevented maintenance measure based on Reliability Centered Maintenance(RCM) analysis, there are some reappearance failures, such as breechblock closedown failure, can't be reduced effectively. After analyzing, it was find that the breechblock is the lowest level FSI in RCM, and it was taken as the cause not the failure itself, the maintenance task is not prevented but repaired or replaced it. Clearly, It is necessary to find the root cause of breechblock exactly and timely, so relevant measure can be adopt to prevent the failure reappearance or reduce its probably. So, Root

Please use the following format when citing this chapter:

Song, Wenyuan, Kang, Jianshe, Shi, Lianyan, Wang, Yabin, 2006, in International Federation for Information Processing (IFIP), Volume 207, Knowledge Enterprise: Intelligent Strategies In Product Design, Manufacturing, and Management, eds. K. Wang, Kovacs G., Wozny M., Fang M., (Boston: Springer), pp. 205-210. 
Cause Analysis (RCA) method is used in this paper.Considering the default of traditional RCA, A perfectly cycle root cause analysis method is present based on methods from references ${ }^{[2,3,4]}$.

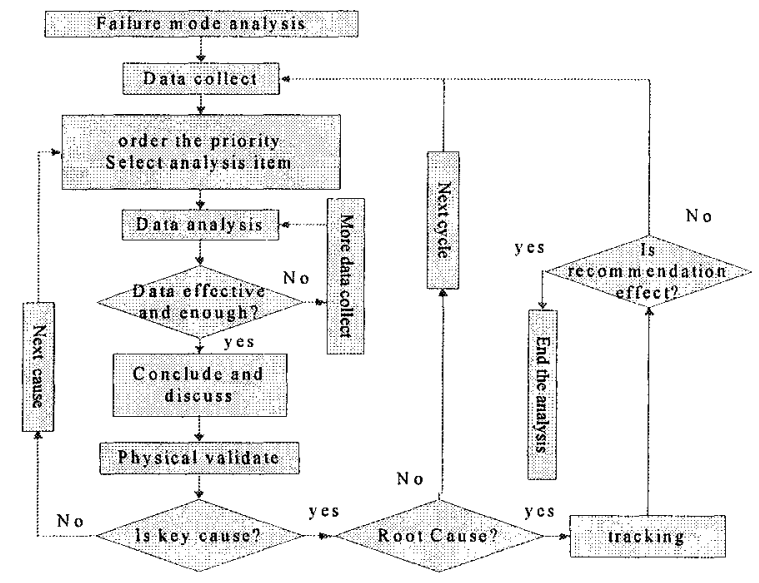

Figure 1. improved RCA analysis process

\section{ROOT CAUSE ANALYSIS AND ITS IMPROVED}

The originally root cause analysis method was presented by America navy nuclear department in 1970's. While until 1990's, root cause analysis method was gradually perfected and could be used in every walk of life, and attracted the eyes of America government, and military. And then there are many special website of RCA was founded and running, and tenth types commercial software about it were developed, such as Apollo、PROACT, Reason、TapROOT、Inhouse System. In 1992, DOE-NE- STD-1004-92 [5], a guide handbook of root cause analysis, was published by America Department of Energy (DOE). According to the result of 2001 RCA applying investigation by plant-maintenance Resource Center of Australia ${ }^{[6]}$, RCA is used widely in nuclear energy, environment, oil, industry machine maintenance and body healthy with un-imaging profit.

As a general designation, RCA has several representations in practice, but all these representations have a similar essence step, it can be described in 5 steps:

- Preserving Failure Data 
- Ordering the Analysis

- Analyzing the Data

- Communicating Findings \& Recommendations

- Tracking for Success

Whereas, there are some defaults of traditional RCA in analyzing military materiel, such as none specific analysis end point, lacking select criteria of analysis direction, need operating data of long uninterrupted working period - it is especially unsuitable for military materiel, etc.

According to the feature of military materiel, an improved RCA method is presented in this paper, limited by the space, figure 1 gave the analysis flow, and the detail analysis step is described with its application on artillery below.

\section{ROOT CAUSE ANALYSIS OF BREECHBLOCK}

\subsection{Analyzing the failure modes of breechblock}

The first step is describing the work principle detail, analyzing the key failure mode and cause by backfit FMEA. As an important part of artillery, breechblock has a multi-function. While firing, it is used to pin the shell pumer, burning the powder, and at the same time closedown the chamber with powder flask in order to forming a high temperature and high pressure gas in powder chamber so that the shell can be obtained a certain original velocity and revolving velocity. After firing, it is used to draw out the powder flask in order to backfill the next shell and blaze away. The failure mode and cause analysis see table 1.

Table 1. Failure Mode and Cause Analysis table

\begin{tabular}{|c|c|c|c|c|c|c|}
\hline \multirow{2}{*}{$\begin{array}{l}\text { Describing } \\
\text { Failure } \\
\text { mode }\end{array}$} & \multicolumn{3}{|c|}{ Effected factors } & \multirow{2}{*}{$\begin{array}{l}\text { Effect and } \\
\text { probably } \\
\text { of cause }\end{array}$} & \multirow{2}{*}{$\begin{array}{l}\text { Simul } \\
\text { ating } \\
\text { result }\end{array}$} & \multirow{2}{*}{$\begin{array}{l}\text { note } \\
\text { the key } \\
\text { cause }\end{array}$} \\
\hline & $\begin{array}{l}\text { Component } \\
\text { s/design }\end{array}$ & $\begin{array}{l}\text { Operating / } \\
\text { maintenance }\end{array}$ & $\begin{array}{l}\text { Environme } \\
\text { nt factors }\end{array}$ & & & \\
\hline & No.1 & & & & & \\
\hline & No. 2 & & & & & Key 1 \\
\hline & $\cdots$ & & & & & \\
\hline \multirow{4}{*}{ Mode 1} & & Operating & & & & Key 2 \\
\hline & & & Factor 1 & & & \\
\hline & & & Factor 2 & & & Key 3 \\
\hline & & & $\cdots$ & & & \\
\hline $\begin{array}{l}\text { Mode } 2 \\
\ldots\end{array}$ & & & & & & \\
\hline
\end{tabular}




\subsection{Cycle analyzing the cause-result chain}

The second step is to build the failure cause-result(key) chain/tree of the objective breechblock failure mode by using RCA. Based on the cause-result chain, the cycle on the chain should be analyzed one by one until the key cause is found. Then all causes of the key cause in the chain one by one until the next key cause is found. And analyzing every level causes ordinal, until the root cause is found.

1. Building the cause-result chain of breechblock failure

For the breechblock, its failure cause-result chain can be protract according to system structure. All the physical relationship should be described in the cause-result chain. And the cause-result chain should extend to the first circle which is deviated the working environment of artillery, or the circle is no longer belong to maintenance measure, such as improve design technology, personnel training and so on. We call this point/circle the end point of whole cycle. Figure 2 show the cause-result chain of breechblock failure.

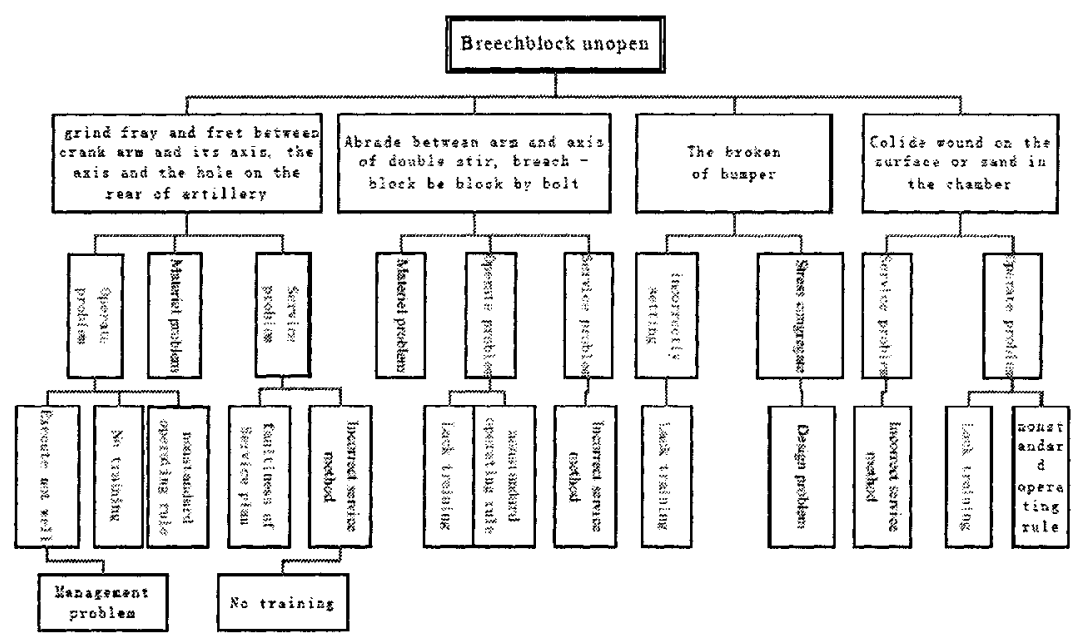

Figure 2. the cause-effect chain of breechblock

\section{Classifying the cause}

In general, cause of a materiel, such as artillery, can be classed in several types: components failed itself or son-components failed, operating rule, maintenance measure, environment cause, arts and crafts, design limitation and management problem and so on. All of these cause or part of them may be include in every layer.

3. Cycle flow 
According to the analysis above, the flow of root cause analysis can be build as figure 1 。

\subsection{Determined root}

In analysis, it is found that the main cause of insurance pry axes broken is the congregated of stress in oriented notch, which cause the crack appear and grown gradually in breechblock opening and closedown. When the crack extended to a limited point, the insurance pry axes broken subsequently. For this matter, there is no any suitable and effective maintenance task, such as 7 type preventive maintenance task based on RCM, CBM and even the proactive maintenance technology arisen recently, can be found by analysis. The only effective measure is redesign. By redesign, the structure can be improved. And the work of redesign is off the environment of breechblock operation and maintenance.

According to the guide line of end point judge, it can be concluded that the design limitation is the root cause of breechblock failure.

\subsection{Recommendations and tracking}

The recommendation is improve the structure and material of insurance pry axes. figure 3 to figure 5 show the scenario.

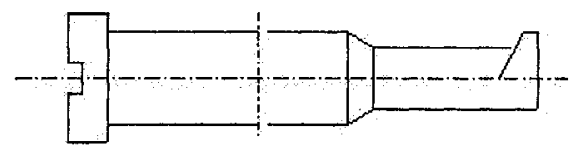

Figure 3. the originally insurance pry axes

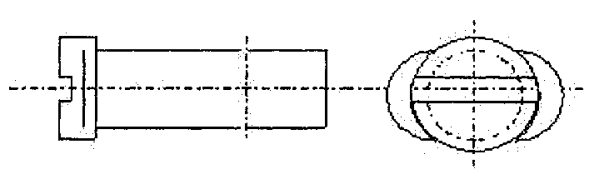

Figure 4. the shape of insurance pry axes improved

The aim of tracking is to checkout whether the recommenda -tion is effectiveness, the execution is correct and the result realized the object scheduled. By tracking, the execution of recommendation can be controlled and improved on real time, and fresh problem can be prevent on time. In this case, tracking work include several aspect as follow: 


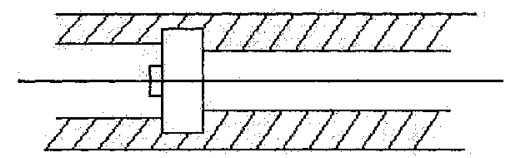

Figure 5. the hole shape of insurance pry axes

- Whether the circle load of insurance pry axes improved beyond the permitted limited;

- Whether the mean life of insurance pry axes improved longer enough;

- Whether the axes improved achieved the engage function in design;

- Whether insurance pry axes improved can avoided the similar broken.

According to the statistical data, the insurance pry axes improved has not broken in training since the refit. And the design function was achieved. So it can be concluded that the design limitation is the root cause of breechblock failure in deed. Thus, the analysis process can be finished, and the investigate report can be finalized.

\section{CONCLUSION}

Clearly, the improved RCA is effective in finding the root cause of breechblock closedown failure, and validating the legitimacy of recommendation. The cycle analysis and the rule of RCA end point judge, presented in this paper, is effectiveness in root cause analysis of breechblock failure despite its immature. And the lack of RCMA can be fetched up.

\section{REFERENCES}

1. FENG Xun-xin et. al. Study of cause-result relationship of common failure in selfpropellant artillery, vehicle \& power Technology 1999 (03) : p32-34.

2. Ronald L. Hughes, Analysis: RCM Versus RCA, Maintenance Resources On-Line Magazine,May/Jun 2002.

3. Robert J.Latino, Root Cause Analysis-Quality of Process? Reliability Center Inc.May 1998.

4. Robert J. Latino, The End of RCA, How, and Why, TPMOnline.com Reliability Center, Inc - April/May 2001.

5. Doe-Ne-Std-1004-92 Root Cause Analysis Guidance Document. 2.1992.

6. Plant Maintenance Resource Center 2001 "Root Cause Analysis" Survey Result http://www.plant-maintenance.com/index.shtml. 